Editor Office : LPPM Sekolah Tinggi Teknologi Pagar Alam, Jln. Masik Siagim No. 75 Simpang Mbacang, Pagar Alam, SUM-SEL, Indonesia Phone : +62 852-7901-1390.

Email : ngabdimas@lppmsttpagaralam.ac.id | ejournal@1ppmsttpagaralam.ac.id Website : https://ejournal.lppmsttpagaralam.ac.id/index.php/ngabdimas

\title{
Pelatihan Pembuatan Aplikasi E-Learning (Edmodo) Pada Guru SMPN 1 Pagar Alam
}

\author{
Desi Puspita \\ Program Studi Teknik Informatika; Sekolah Tinggi Teknologi Pagaralam (STTP) \\ Jl. M. Siagim No.75 Kel. Karang Dalo, Dempo Tengah, Kota Pagar Alam \\ Telp/Fax: (0730) 621916 \\ e-mail: desiofira1@.gmail.com.
}

\begin{abstract}
Abstrak
Pembelajaran yang baik dapat menghasilkan output pembelajaran yang baik juga, sehingga dihasilkan tatanan yang baik juga, SMPN 1 Pagaralam lembaga pendidikan menengah pertama yang mendasari bagi pendidikan menengah selanjutnya, sebagai lembaga pendidikan pertama maka dasar pendidikan harus di tata dan dikelola dengan baik sehingga siswa bisa mengikuti pembelajaran pada masa mendatang, dengan demikian maka SMPN 1 Pagaralam harus memperbaiki sistem, sarana dan cara untuk dihasilkan pendidikan yang baik, salah satunya sarana pendidikan, sarana ini berupa aplikasi e-learning menggunakan aplikasi edmodo, SMPN 1 Pagaralam menyadari agar dihasilkan output pembelajaran yang baik diperlukan sarana pendukung yang handal. Metode yang digunakan pada pelatihan ini adalah ceramah dan praktek langsung keaplikasi. Pada awal pelatihan dilakukan pre tes untuk mengetahui pemahaman peserta pelatihan dan hasilnya $85 \%$ peserta mengetahui e-learning tetapi belum pernah menggunakannya sehingga pemahamannya menjadi kurang bagus, pada akhir pelatihan dilakukan pos tes, pos tes dilakukan untuk mengetahui keberhasilan pelatihan dan hasilnya seluruh peserta mampu mengelola dan membuat sistem pembelajaran e-learning dengan edmodo.
\end{abstract}

Kata kunci-Pembelajaran, SMP, Pengabdian, Edmodo, Pelatihan, Materi.

\section{PENDAHULUAN.}

Sekolah Tinggi Teknologi Pagaralam (STTP) institusi Pendidikan Tinggi (TI) yang pada operasionalnya mengikuti dan melaksanakan Tri Dharma Perguruan Tingg, salah satunya adalah Pengabdian kepada masyarakat atau PkM, PkM menjadi kegiatan wajib yang harus dilaksanakan oleh civitas STTP, sehingga pelatihan pembuatan aplikasi edmodo ini merupakan semangat berbagi yang ada pada civitas STTP, ini dilakukan karena sesuai dengan keahlian civitas STTP dalam bidang Teknologi Informasi (TI). Perkembangan teknologi informasi dan komunikasi (TIK) khususnya teknologi pendukung terlaksananya kegiatan pembelajaran saat ini sangat banyak dan menawarkan kemudahan-kemudahan sesuai ke unggulan masing-masing, salah satunya e-learning yang bisa di manfaatkan sebagai sarana pembuatan aplikasi pengolahan data pembelajaran. Media ini sangat banyak sekali digunakan di sebagai sarana pengolahan data yang sangat familiar.

Penggunaan e-learning (edmodo) sebagai media/sarana pembuatan aplikasi pengolahan data pembelajaran ini sangat di sarankan karena memiliki menu-menu yang sesuai dengan standar penulisan yang di sarankan para ahli yang kompeten yang lebih dahulu mempelajari dan menggunakan aplikasi ini, sehingga pada saat penyusunan e-learning dengan edmodo ini pembuat aplikasi tinggal klik menu-menu yang di maksud maka di dapat hasil tulisan (pengolah data) yang baik (standar), selain itu edmodo merupakan software pengolah data pembelajaran yang mudah di dapat dan murah, selain itu apa bila ingin meng-upgrade, atau mengganti ke versi terbaru developer menyediakan dengan mudah. Dari pemaparan diatas dituntut agar para peserta harus selalu meningkatkan kualitas pembelajaran dengan menggunakan semua resource terkait, sehingga dipandang perlu untuk diadakan pelatihan pembuatan aplikasi pengolahan data pembelajaran. Berdasarkan informasi yang diperoleh dari para Guru di SMPN 1 PAGARALAM, masalah yang dihadapi dapat diidentifikasikan sebagai berikut.

1. Para Guru belum terlalu memahami elearning terutama bagi guru senior. 
2. Para Guru belum dapat membuat aplikasi penunjang belajar dengan baik.

3. Para Guru belum memahami dengan baik logika-logika penyusunan desain edmodo.

Sehingga dengan pelatihan ini dianggap peserta mampu nantinya melaksanakan perkuliahan daring atau melalui fasilitas e-learning yang sudah tersedia.

\section{METODE.}

Pada pengabdian ini, pelaksanaan pelatihan dilakukan secara mandiri oleh dosen pengabdi, dan berbarengan kuliah kerja nyata yang dilakukan para mahasiswa sehingga pada pelaksanaanya mahasiswa membantu dosen melaksanakan pelatihan. Metodologi yang digunakan yaitu menyimak (menonton) bersama, membaca (modul), memahami tools aplikasi (Software) dan berinteraksi secara langsung (Aplikatif) dengan software. Sehingga peserta mampu memahami materi yang disampaikan oleh narasumber.

\subsection{Pengabdian kepada Masyarakat.}

Pengertian dari pengabdian masyarakat, suatu kegiatan bertujuan untuk membantu masyarakat dalam beraktivitas tanpa mengharapkan imbalan. Dimana secara umum program PkM ini dirancang lembaga pengabdian di Perguruan Tinggi untuk memberikan kontribusi nyata bagi masyarakat, khususnya saat mengembangkan kesejahteraan dan kemajuan. Kegiatan PkM merupakan bagian dari Tri Dharma Perguruan Tinggi. Bentuknya berupa: Bakti Sosial dan Mengajar. Tujuan Pengabdian Masyarakat di Perguruan Tinggi, seperti:

a. Menciptakan inovasi baru teknologi informasi untuk mendorong pembangunan dengan melakukan komersialisasi hasil penelitian, yang dihasilkan kampus;

b. Menyampaikan solusi berdasarkan hasil kajian akademik atas kebutuhan, tantangan, atau persoalan yang dihadapi oleh masyarakat, baik secara langsung maupun tidak langsung;

c. Melaksanakan program kegiatan yang mampu mengentaskan masyarakat tersisih (preferential option for the poor) dalam semua strata, yaitu masyarakat tersisih secara ekonomi, politik, sosial \& budaya;

d. Melaksanakan alih teknologi, ilmu \& seni pada masyarakat untuk pengembangan martabat manusia dan kelestarian sumber daya alam yang ada.

\subsection{E-Learning.}

Saat ini sistem pembelajaran elektronik atau dikenal sebagai "e-learning" merupakan inovasi baru pembelajaran. Menurut (Darmawan, 2014: 10) e-learning merupakan aplikasi internet yang menghubungkan pendidik dan perserta didik padasebuah ruang belajar online. Cisco (2001) yang di kutip Darmawan (2014: 27) menjelaskan filosofis E-learning sebagai berikut. Pertama, Elearning merupakan penyampaian informasi, komunikasi, pendidikan, pelatihan secara on-line. Kedua, E-learning menyediakan seperangkat alat yang bisa memperkaya nilai belajar secara konvensional (model belajar konvensional, kajian terhadap buku teks, CD-ROM, dan pelatihan berbasis komputer), sehingga dapat menjawab tantangan perkembangan globalisasi saat ini.

\subsection{Edmodo.}

Edmodo ini dikembangkan akhir tahun 2008 Nic Borg dan Jeff Ohara berkeyakinan perlunya dikembangkan lingkungan sekolah yang terhubung dengan semua aktifitas didunia. sehingga tidak ada kesenjangan antara kehidupan siswa di sekolah dengan kehidupan kesehariannya. Edmodo ini media social network microblogging aman bagi siswa dan guru. Pada situs ini orang tua pun dapat bergabung serta berkomunikasi dengan guru dan orang tua siswa lain, selain itu tentu saja dengan putra atau putri mereka sendiri. Sekarang Edmodo sudah berkembang pesat dan telah mempunyai \pm 7 juta akun terdiri dari guru dan murid. Tahun 2010 Edmodo meluncurkan "subjek" dan "penerbit" masyarakat, media digital perpustakaan, pusat bantuan, dan rekening induk untuk berkomunikasi dengan guru, orang tua \& siswa. Edmodo merupakan jejaring sosial untuk pembelajaran berbasis Learning Managent System (LMS). Edmodo memberi fasilitas bagi guru, murid tempat aman untuk berkomunikasi, berkolaborasi, berbagi konten dan aplikasi pembelajaran, pekerjaan rumah (PR) bagi siswa, diskusi dalam kelas virtual, ulangan secara online, nilai dan banyak lagi. Intinya edmodo menyediakan semua yang bisa dilakukan dikelas bersama siswa dalam kegiatan pembelajaran ditambah fasilitas bagi orang tua bisa memantau semua aktifitas anak di edmodo 
asalkan punya parent code untuk anaknya. Edmodo ini sebuah situs diperuntukan bagi pendidik membuat kelas virtual. Situs tersebut gratis dan gampang digunakan selama seorang guru dan murid bisa terhubung dengan internet. Edmodo merupakan sebuah jawaban bagi sebuah ruang kelas virtual nyaman dan aman, dikarenakan :

1. Siswa melakukan interaksi dalam pantauan guru (bebas cyber crime dan cyber bullying).

2. Guru bisa mengunci siswa, dengan demikian hanya bisa membaca dan tak bisa berkomentar pada seisi 'kelas' namun tetap ia bisa berkomunikasi langsung dengan guru.

3. Tak ada orang lain bisa masuk dan melihat kelas virtual tanpa mendapat kode khusus dari guru yang bersangkutan.

4. Guru bisa memulai pertanyaan, menaruh foto atau video, menaruh presentasi bahan ajar, yang semuanya bebas diunduh oleh siswa dan dikomentari.

5. Murid bisa kembali kapan saja untuk mengulang materi diberikan guru, bahkan PR bisa diberikan melalui edmodo.

6. Murid bisa mengumpulkan PR lewat edmodo, tinggal unggah. Edmodo bisa dipadukan dengan situs lain seperti wall wisher, glogster dan lain sebagainya.

7. Guru bisa menaruh nilai pekerjaan siswa sebagai acuan bagi siswa.

8. Kelas virtual yang dibuat guru tidak terbatas, guru bisa menaruh bahan ajar untuk digunakan di angkatan atau tahun ajaran berikutnya.

9. Siswa bisa bekerja sama dengan siswa lain pada grup kecil yang dibentuk gurunya.

10. Saat mengerjakan proyek bersama mereka bisa menaruh semua dokumen diperlukan dalam pengerjaannya.

11. Edmodo memungkinkan guru menaruh bahan ajar yang sangat berguna bagi siswa yang tak masuk atau berhalangan saat melakukan tatap muka.

12. Siswa pendiam bisa bebas berkata dan berpendapat tanpa khawatir dipermalukan sementara si anak tipe aktif bisa posting pertanyaan kapan saja asal ia terhubung dengan internet.

13. Guru dapat mengajarkan tata cara yang berlaku di dunia maya seperti cara berkomentar dan sederet tata krama di dunia maya yang perlu siswanya ketahui.

\subsection{Pre \& Pos Tes.}

Pre tes yaitu bentuk pertanyaan, dilontarkan guru pada murid sebelum memulai suatu pelajaran. Pertanyaan yang ditanya adalah materi yang akan diajar pada hari itu (materi baru). Pertanyaan biasanya dilakukan guru di awal pembukaan pelajaran. Pre tes diberikan dengan maksud mengetahui apakah ada diantara murid yang sudah mengetahui mengenai materi yang akan diajarkan. Pre tes juga diartikan sebagai kegiatan menguji tingkatan pengetahuan siswa terhadap materi akan disampaikan, kegiatan pre tes dilakukan sebelum kegiatan pengajaran diberikan. Manfaat pre tes untuk mengetahui kemampuan awal siswa mengenai pelajaran yang disampaikan. Dengan mengetahui kemampuan awal siswa ini, guru dapat menentukan cara penyampaian pelajaran yang di tempuh nanti.

Pos tes merupakan pertanyaan diberikan setelah pelajaran/materi telah disampaikan. Singkatnya, pos tes ini evalausi akhir saat materi yang di ajarkan pada hari itu telah diberikan, guru memberikan pos tes dengan maksud apakah murid sudah mengerti dan memahami mengenai materi yang baru diberikan pada hari itu. Manfaat diadakan pos tes ini untuk memperoleh gambaran tentang kemampuan yang dicapai setelah berakhirnya penyampaian pelajaran. Hasil pos tes dibandingkan dengan hasil pre tes yang telah dilakukan sehingga diketahui seberapa jauh efek atau pengaruh pengajaran yang dilakukan, disamping sekaligus dapat diketahui bagian mana dari bahan pengajaran yang belum dipahami sebagian besar siswa.

\subsection{Penyelesaian Masalah.}

Sesui permasalahan ini perlu dilakukan pelatihan pembuatan aplikasi edmodo agar peserta mampu mengolah dan membuat fasilitas pembelajaran daring yang mana siswa dapat melakukan pembelajaran dimana saja, sehingga dapat meningkatkan output SMPN 1 Kota Pagar Alam yang menerapkan juga pembelajaran berbasis digital, sehingga meningkatkan kepercayaan calon peserta didik karena SMPN 1 Kota Pagar Alam memiliki sarana pembelajaran yang lebih baik dan lebih lengkap bila dibanding Sekolah-sekolah umumnya.

3. PEMBAHASAN DAN HASIL. 


\subsection{Realisasi \& Pemecahan Masalah.}

Pelaksanaan dan pemecahan permasalahan pembuatan aplikasi edmodo pada SMPN 1 Kota Pagar Alam, yang dilaksanakan pengabdi sebagai narasumber, pelaksanaan dilakukan satu hari dengan rincian acara sebagaimana teruraikan pada penjelasan tabel dibawah ini:

Tabel 1. Kegiatan

\begin{tabular}{|l|l|c|}
\hline \multicolumn{1}{|c|}{ Waktu } & \multicolumn{1}{|c|}{ Materi } & Penyaji \\
\hline $08.00-09.00$ & Pre Test & \\
$09.00-09.30$ & Pengantar teknologi e-learning dan uraian edmodo & \\
\hline $09.30-12.00$ & Panduan pembuatan akun dan input data ke dalam aplikasi & \multirow{2}{*}{ Desi Puspita } \\
& edmodo & \\
$12.00-12.30$ & Ishoma & \\
$12.30-13.00$ & Post-test & \\
\hline
\end{tabular}

Pada penjelasan tabel 1, terlihat susunan kegiatannya terdiri dari: Pertama, pre tes dilakukan pertama atau awal acara hal ini dilakukan untuk mengetahui pemahaman peserta pelatihan terhadap aplikasi edmodo yang menjadi bahan utama pembelajaran yang dilatihkan pada para peserta. Kedua, menjelaskan tentang perkembangan, manfaat, efisiensi, efektiftas dan perkiraan ke depan tentang arah pendidikan ke depan yang menggunakan sistem digital sehingga arah pendidikan menggunakan sistem pendidikan jarak jauh (PJJ) dan penjelasan sebagai gambaran awal aplikasi yang konsen terhadap pendidikan jarak jauh menggunakan edmodo, diperkenalkan tata cara membuat aku, mengelola dan menginputkan data-data pelajaran, cara berkomunikasi dengan edmodo dan sebagainya. Ketiga, praktek pembuatan akun edmodo atau praktek pembuatan sistem sarana pembelajaran dengan menggunakan fasilitas edmodo setelah seluruh peserta memahami teori tahap kedua tadi, pembuatan akun dan memasukan data pelajaran dalam hal ini untuk sementara peserta diminta untuk mengikuti modul pembelajaran dan bimbingan narasumber agar pemahamannya semakin baik. Keempat, bagian akhir dari kegiatan ini melakukan tes lagi terhadap seluruh peserta dalam hal ini untuk mengetahui pemahaman peserta terhadap materi yang disampaikan dan mengukur tingkat keberhasilan kegiatan yang dilakukan, caranya dilakukan tes lalu dibandingkan dengan hasil pre tes maka didapatkan gap antara pre dan pos tes.

\subsection{Pembahasan \& Hasil.}

Sesuai uraian kegiatan pengabdian pembuatan aplikasi yang dilaksanakan pada SMPN 1 Kota Pagar Alam sesuai uraian 3.1 diatas maka penjelasan hasilnya adalah sebagai berikut: Pertama, hasil dari pre tes seluruh peserta $(100 \%)$ belum pernah menggunakan e-learning (edmodo) walau pun beberapa orang peserta sudah mengetahui pembelajaran berbasis e-learning dan ini menyimpulkan bahwa kagiatan sangat penting dilakukan dan penjelasan atau pelatihan harus dilakukan dari dasar sekali. Kedua, penjelasan teori tentang perkembangan dan perkiraan kedepan pendidikan yang mengarah pada sistem pendidikan PJJ, peserta menjadi tercerahkan dan memahami dengan baik perkembangan pendidikan dan teknologi pendidikan yang semakin modern sehingga mereka bersemangat mempelajari edmodo ini agar tidak ketinggalan zaman. Ketiga, praktek pembuatan akun edmodo dan memasukan data pelajaran yang dimiliki peserta kedalam akun yang dimiliki berdasarkan bimbingan dan arahan dari narasumber, dan hasilnya seluruh peserta mampu dengan baik melaksanakan pembuatan akun dan tugas menginputkan data pelajaran kedalam edmodo dengan baik, bahkan peserta mampu merubah-rubah tampilan edmodo dan sistem pembelajaran didalamnya menjadi lebih menarik, selain itu peserta juga mampu memahami dengan baik seluruh tools dan fitur yang ada sehingga proses pembelajaran menjadi lebih baik seperti fitur chat (diskusi), pembuatan tugas, PR dan sebagainya sehingga proses pembelajaran pada edmodo sama dengan proses pembelajaran yang dilaksanakan secara tatap muka langsung didalam kelas. Keempat, kegiatan terakhir pada pelatihan ini dilakukan tes lagi, pos tes untuk mengukur tingkat keberhasilan pelatihan dan memahami tingkat pemahaman peserta pelatihan terhadap pelatihan yang dilakukan, dan hasilnya sesuai penjelasan ketiga diatas peserta dengan baik mampu mengolah data dan melakukan proses pembelajaran dengan sangat baik sesuai penjelasan dan arahan narasumber dengan baik, bahkan beberapa peserta telah dapat menggunakan 
beberapa fitur tambahan yang belum dijelaskan oleh narasumber sehingga berdasarkan hal ini pelatihan telah berhasil dengan baik dalam pelaksanaannya.

Tabel 2. Keberhasilan Pelaksanaan Kegiatan

\begin{tabular}{|l|l|}
\hline \multicolumn{1}{|c|}{ Materi } & \multicolumn{1}{|c|}{ Hasil } \\
\hline Pendahuluan & $\begin{array}{l}\text { Pendahuluan merupakan tes awal untuk mengetahui } \\
\text { pemahaman peserta terhadap edmodo, hasilnya 100\% belum } \\
\text { pernah menggunakan edmodo. }\end{array}$ \\
\hline Pengantar e-learning \& edmodo & $\begin{array}{l}\text { Peserta memahami teknologi e-learning, PJJ dan pemahaman } \\
\text { cara buat akun, cara mengolah data pelajaran pada edmodo. }\end{array}$ \\
\hline Praktek pembuatan akun & $\begin{array}{l}\text { Peserta mampu membuat akun dan mengolah data secara } \\
\text { aplikatif dalam edmodo dan berhasil dengan baik. }\end{array}$ \\
\hline Penutup & $\begin{array}{l}\text { Tahap akhir yang dilakukan pada pengabdian ini dan hasilnya } \\
\text { seluruh peserta mampu mengelola data dalam edmodo. }\end{array}$ \\
\hline
\end{tabular}

Pada kegiatan pengabdian yang dilakukan meningkatkan rasa peduli dan meningkatkan empati antar sesama masyarakat untuk saling mensejahterakan, dari sini bisa di pahami hasil dari kegiatan pengabdian yang dilakukan ini softskills para peserta yang mengikuti pelatihan meningkat dengan sangat baik dan pelatihan berhasil dengan sangat baik, sehingga peserta pelatihan menjadi lebih optimis dalam menghadapi masa depannya ini memberikan keuntungan bagi SMPN 1 Kota Pagar Alam karena masyarakat semakin percaya dan bagi STTP dengan pengabdian dan pelatihan ini mendapat calon peminat baru kuliah di STTP dan meningkatkan kepercayaan kemampuan alumni yang sangat baik, bisa diidentifikasi berikut merupakan hasilnya:

a. Para peserta Pelatihan Guru SMPN 1 Kota Pagar Alam mempunyai pengetahuan dan pemahaman yang baik tentang aplikasi edmodo sebagai sarana pendukung pendidikan.

b. Seluruh peserta Guru SMPN 1 Kota Pagar Alam menjadi paham terhadap teknologi informasi yang aplikatif untuk mendukung pengolahan data pendidikan pada edmodo.

c. Pimpinan SMPN 1 Kota Pagar Alam sudah terbantu dalam pemberian pemahaman terhadap teknologi informasi up to date yang aplikatif pada para guru.

d. Para Guru peserta pelatihan menjadi lebih merasa percaya diri saat mengajar.

\section{KESIMPULAN}

Pada pelaksanaan program pengabdian masyarakat yang dilakukan di SMPN 1 Kota Pagar Alam dengan tujuan melatih Guru dalam melakukan pengolahan data pembelajaran dengan edmodo, didapatkan kesimpulan sebagai berikut:

a. Menambah softskills para Guru bidang Teknologi Informasi khususnya pengembangan sarana untuk pendidikan jarak jauh.

b. Pada proses pembelajaran secara langsung (praktek) pada program (aplikasi) ternyata sudah mampu meningkatkan semangat belajar menjadi lebih giat pada aplikasi edmodo.

c. Mampu meningkatkan rasa kepercayaan diri peserta pelatihan dengan kemampuannya ketika terjun di masyarakat yang memerlukan.

d. Membantu guru pelajaran TIK dalam hal memahamkan para Guru yang lain terhadap suatu aplikasi tertentu, dalam hal ini aplikasi edmodo.

\section{SARAN}

Berdasarkan pengalaman yang dilihat dan dirasakan penulis saat melakukan pengabdian pembuatan aplikasi e-learning dengan edmodo yang dilaksanakan di SMPN 1 Kota Pagar Alam maka penulis dalam hal ini bisa memberikan saran:

a. Memperpanjang masa pengabdian agar penyampaian materi menjadi lebih baik.

b. Memperbanyak instansi atau lembaga untuk tempat pengabdian

c. Memperbaiki manajemen pengelolaan pengabdian yang lebih baik dan transparan.

d. Membuat SOP dan standard prosedur pengabdian yang baik.

UCAPAN TERIMA KASIH 
Pengabdi berterima kasih kepada semua pihak: kawan-kawan dosen, mahasiswa yang membantu, LPPM STTP, SMPN 1 Kota Pagar Alam.

\section{DAFTAR PUSTAKA}

[1] Menristekdikti. 2016. Panduan Pelaksanaan Penelitian dan Pengabdian Masyarakat di Perguruan Tinggi Edisi X Tahun 2016. hlm. 4.

[2] Muslim, B. 2018. Pelatihan aplikasi editing video dengan filmora., Laporan Pengabdian Kepada Masyarakat, LPPM STT Pagaralam.

[3] Muslim, B. 2018. Pelatihan Pembuatan Blog Bagi Guru Ma Ponpes Darul Mutaqin Kota Pagaralam. NGABDIMAS. Vol 1. No.1. Bulan Juni, Hal. 6-11

[4] B. Muslim, Pengantar teknologi informasi. Yogyakarta: Deepublish, 2017.

[5] Muslim, B. (2018). Analisis system informasi (SI) terintegrasi di Perguruan Tinggi (PT) (Studi Kasus: STT Pagaralam). Jurnal Teknologi Informasi MURA, Vol 10. Page 83-91.

[6] Muslim, B (2014). Analisis rencana aplikasi teknologi informasi pada STT Pagar Alam. Proseding semnastik dan Magma. Issue: Aplikasi Teknologi dan sistem Informasi. PPP UBD Pres. Pages 397-404.

[7] Hutchinson E. Sarah and Sawyer C. Stacey, 2000, Computers, Communications \& Information, McGraw Hill Companies Inc.

[8] Indonesia Services Education HP Tim, 2001, Manajemen Sistem Belajar Di Dunia Maya, Majalah Info Komputer.

[9] M.H Jogiyanto, 1995, Pengenalan Komputer, Andi Offset Yogyakarta.

[10] Horsley, M., Knight, B., \& Huntly, H. 2010. The role of textbooks and other teaching and learning resources in higher education in Australia: Change and continuity in supporting learning. IARTEM 1-Journal. 3(2). 43-61.

[11] Sadiman, A.S., Rahardjo, R., Haryono, A., \& Rahardjito. 2006. Media pendidikan: Pengertian, pengembangan, dan pemanfaatan. Jakarta: Rajagrafindo Persada.

[12] Isro'Mukti, Y. (2017). Sistem Informasi Madrasah Aliyah Negeri Pagar Alam Berbasis Web. Indonesian Journal of Computer Science, 6(2), 192-205.

[13] Mukti, Y. (2017). Perencanaan Strategis Sistem Informasi Dan Teknologi Informasi Pada Sekolah Menengah Kejuruan Negeri 2 Pagar Alam. JURNAL ILMIAH BETRIK: Besemah Teknologi Informasi dan Komputer, 8(02), 83-92.

[14] Arif, A., \& Mukti, Y. (2017). Rancang Bangun Website Sekolah Menengah Pertama (SMP) Negeri 8 Kota Pagar Alam. JURNAL ILMIAH BETRIK: Besemah Teknologi Informasi dan Komputer, 8(03), 156-165.

[15] Isro'Mukti, Y. (2018, October). Sistem Informasi Manajemen Aset Sekolah Tinggi Teknologi Pagaralam Berbasis Web. In Seminar Nasional Teknologi Informasi dan Komunikasi (SEMNASTIK) (Vol. 1, No. 1, pp. 632-638).

[16] Mukti, Y. (2018). Rancang Bangun Website Sekolah Dengan Metode User Centered Design (UCD). JURNAL ILMIAH BETRIK: Besemah Teknologi Informasi dan Komputer, 9(02), 84-95.

[17] Mukti, Y. (2018). Pelatihan Maintance Komputer SMAN Pagar Gunung. NGABDIMAS, $1(1), 47-51$.

[18] Mukti, Y. I. (2019). Implementasi Jaringan Hotspot Kampus Menggunakan Router Mikrotik. Indonesian Journal of Computer Science, 8(2), 130-138.

[19] Mukti, Y. I., \& Puspita, D. (2019). Sistem Informasi Peringatan Dini Bencana Pada Kota Pagar Alam Berbasis Mobile. Jusikom: Jurnal Sistem Komputer Musirawas, 4(2), 65-74.

[20] Mukti, Y. I. (2019). SISTEM INFORMASI MONITORING KESEHATAN MASYARAKAT BERBASIS WEB MENGGUNAKAN METODE UNIFED MODELLING LANGUAGE. Jusikom: Jurnal Sistem Komputer Musirawas, 4(1), 1-8.

[21] Mukti, Y. I., \& Puspita, D. (2019, December). Web Based Disaster Early Warning System on Pagar Alam City. In Conference SENATIK STT Adisutjipto Yogyakarta (Vol. 5, pp. 309-316).

[22] Isro'Mukti, Y., \& Puspita, D. WEB BASED DISASTER EARLY WARNING SYSTEM ON PAGAR ALAM CITY.

[23] Puspita, D., \& Isro’Mukti, Y. (2019, December). Web-Based Culture Information System 
of Literature Besemah City of Pagar Alam. In Conference SENATIK STT Adisutjipto Yogyakarta (Vol. 5, pp. 303-308). 